\title{
The overexpression of BAMBI and its involvement in the growth and invasion of human osteosarcoma cells
}

\author{
LU ZHOU $^{1 *}$, JIN PARK $^{5 *}$, KYU YUN JANG ${ }^{2}$, HO SUNG PARK $^{2}$, SAJEEV WAGLE $^{1}$, \\ KYU HYUN YANG ${ }^{5}$, KWANG-BOK LEE ${ }^{1}$, BYUNG-HYUN PARK ${ }^{3}$ and JUNG RYUL KIM ${ }^{1,4}$
}

\author{
Departments of ${ }^{1}$ Orthopaedic Surgery, ${ }^{2}$ Pathology, ${ }^{3}$ Biochemistry, and ${ }^{4}$ Research Institute for Endocrine Sciences, \\ Chonbuk National University Medical School, Jeonju 561-756; ${ }^{5}$ Department of Orthopaedic Surgery, \\ College of Medicine, Yonsei University, Seoul, Republic of Korea
}

Received May 14, 2013; Accepted June 17, 2013

DOI: $10.3892 / o r .2013 .2569$

\begin{abstract}
The pseudoreceptor BAMBI (bone morphogenetic protein and activin membrane-bound inhibitor), formerly known as NMA, is an inhibitor of the TGF- $\beta$ signaling pathway. BAMBI exhibits structural homology to TGF- $\beta$ RI but lacks an intracellular kinase domain. In most of the high-grade carcinomas, the degree of BAMBI expression is abnormally increased, which leads to the proliferation and metastasis of tumor cells. Recent studies have reported that BAMBI is involved in the Wnt- $\beta$-catenin pathway that regulates the proliferation and metastasis of tumor cells. However, little is known about the role of BAMBI and $\beta$-catenin in human osteosarcoma. Given the above background, we examined the role of BAMBI in the pathophysiology of osteosarcoma. Using immunohistochemical staining and western blot analysis, the degree of the expression of BAMBI and $\beta$-catenin was significantly higher in osteosarcoma specimens compared with normal tissues. With the overexpression of BAMBI, mediated by adenovirus, the degree of invasion and migration was significantly increased and the proliferation of U2-OS osteosarcoma cells was stimulated. Transwell analysis showed that BAMBI increased the invasion of osteosarcoma cells and upregulated the secretion of matrix metalloproteinases (MMPs), which was demonstrated by gelatin zymography. Fluorescence-activated cell sorting (FACS) analysis showed a significant arrest in cell cycle progression at $\mathrm{G}_{0} / \mathrm{G}_{1}$ in osteosarcoma cells transfected with siRNA targeting BAMBI. With the overexpression of BAMBI, mediated by the adenovirus, however, there was a decrease in the number of cells at $\mathrm{G}_{0} / \mathrm{G}_{1}$.
\end{abstract}

Correspondence to: Professor Jung Ryul Kim, Department of Orthopaedic Surgery, Chonbuk National University Medical School, 567 Baekje-daero, Deokjin-gu, Jeonju, 561-756, Republic of Korea E-mail: jrkeem@jbnu.ac.kr

*Contributed equally

Key words: cell cycle, BAMBI, $\beta$-catenin, osteosarcoma, invasion, proliferation
Consistent with the findings that cell growth was increased, BAMBI promoted the transition from $G_{0} / G_{1}$ to $G_{2} / M$ in the osteosarcoma cells. Our results suggest that BAMBI plays a key role in the pathogenesis and progression of osteosarcoma by regulating the expression of $\beta$-catenin and other signaling molecules via the pathways involved in the regulation of the cell cycle. This relationship between BAMBI and its involvement in the regulation of the cell cycle would provide a possibility that the BAMBI may be a new target for gene therapy.

\section{Introduction}

Osteosarcoma is the primary malignant bone tumor that occurs the most prevalently in young people. The survival rate has been improved over the past 20 years. It shows an aggressive growth from the primary site. In addition, it often shows micrometastases to the lung before it is being diagnosed (1). A complete removal of the tumor using a wide excision, accompanied by aggressive adjuvant chemotherapy, is the standard treatment modality for osteosarcoma (2). Despite the intensity and modification of chemotherapy, its pulmonary metastasis often leads to fatal outcomes $(3,4)$. Little is known about the exact molecular pathophysiology of osteosarcoma. It is, therefore, imperative that it be clarified to improve the long-term survival of patients with osteosarcoma, and to contribute to the development of targeted anticancer therapies.

Transforming growth factor- $\beta$ (TGF- $\beta$ ) is a multifunctional cytokine that controls a variety of fundamental biological activities such as the proliferation, differentiation, migration, adhesion and apoptosis of the cells (5). That is, the TGF- $\beta$ signaling pathway has an inhibitory effect on the proliferation of tumor cells. Therefore, blockage of the TGF- $\beta$ signaling pathway is involved in the progression of many carcinomas (6). It has actually been reported that the human tumorigenesis is characterized by inactivating mutations of type II receptor (T $\beta$ RII), Smad2 and Smad4. In addition, there are also some reports that the TGF- $\beta$ receptor is often downregulated in tumor cells, or otherwise unavailable at the cell surface, thus allowing tumor cells to escape the growth inhibitory activities (7).

The pseudoreceptor BAMBI (bone morphogenetic protein and activin membrane-bound inhibitor), formerly known 
as NMA, is an inhibitor of the TGF- $\beta$ signaling pathway. BAMBI exhibits structural homology to TGF- $\beta$ RI but lacks an intracellular kinase domain (8). In most of the high-grade carcinomas, the degree of BAMBI expression is abnormally increased, which leads to the proliferation and metastasis of tumor cells $(9,10)$. In HepG2 hepatoma cells, transcription of BAMBI is regulated via a feedback loop which confers binding of Smad3 and Smad4 to the Smad-responsive elements of the BAMBI promoter. A recent study has also suggested that BAMBI is involved in Toll-like receptor 4 and lipopolysaccharide mediated hepatic fibrosis (11). Moreover, $\beta$-catenin can promote the BAMBI expression indirectly (9). Therefore, it is worth examining whether BAMBI regulates the Wnt signaling.

Wnt acts through a $\beta$-catenin-dependent or canonical Wnt pathway (12), where $\beta$-catenin is considered as the key component of the above signaling pathway. It consists of highly conserved secreted ligands that bind to cell-surface receptors called frizzled and lipoprotein receptor related protein (LRP) (13). In the presence of Wnt ligands, $\beta$-catenin is accumulated in the cytosol and thereby blocks its degradation. Stabilized $\beta$-catenin translocates into the nucleus, and forms a complex with lymphocyte enhancer factor (LEF)/T-cell factor (TCF) family of transcription factors to activate target genes, many of which are involved in the development and progression of tumors (14). It has, therefore, been proposed that the Wnt pathway is involved in the pathogenesis and progression of many human malignancies.

To date, however, no studies have clarified the mechanisms by which the Wnt pathway is involved in the progression of osteosarcoma. Given the above background, we examined the role of BAMBI in the pathophysiology of osteosarcoma and found that its overexpression affected the intracellular expression of $\beta$-catenin, a mediator of the Wnt signaling pathway, and thereby had an effect on the invasion and proliferation of osteosarcoma cells.

Our results indicate that the tumor cell motility and invasion can be blocked by the inhibition of BAMBI using RNA interference. This confirms that BAMBI plays a key role in the pathogenesis of osteosarcoma. Taken together, our results provide evidence linking the Wnt signaling to the progression of human osteosarcoma.

\section{Materials and methods}

Cell culture and reagents. The human osteosarcoma cell line U2-OS, was purchased from the American Type Culture Collection (ATCC, Rockville, MD, USA), and HEK293A cells were from stock maintained in our laboratory. These cells were grown at $37^{\circ} \mathrm{C}$ under a humidified $5 \% \mathrm{CO}_{2}$ atmosphere in DMEM medium supplemented with $10 \%$ fetal bovine serum and $100 \mathrm{U} / \mathrm{ml}$ penicillin, $100 \mu \mathrm{g} / \mathrm{ml}$ streptomycin and $2.5 \mu \mathrm{g} /$ $\mathrm{ml}$ amphotericin B. All reagents were purchased from Sigma (St. Louis, MO, USA) unless otherwise noted.

Tissue preparation. Eleven paraffin-embedded samples of human osteosarcoma and normal tissues were obtained from the Chonbuk National University Hospital. All the tissue samples were fixed in a $4 \%$ formalin solution. Each block was cut into $5-\mu \mathrm{M}$ sections and then stained with specific antibodies. All samples were acquired during surgeries, with written patient consent, and stored at $-80^{\circ} \mathrm{C}$ until use.

Transfection of cells. Transient transfections were performed by the reverse transfection technique using Lipofectamine ${ }^{\mathrm{TM}}$ RNAiMAX kit (Invitrogen, Carlsbad, CA, USA). Three sequences and a negative control siRNA were purchased from Bioneer Corp. (Daejon, Korea) and were initially assessed as potential targets for transfection. Preparation and amplification of adenovirus were performed as previously described (15). Adenoviruses encoding BAMBI were created using the ViraPower Adenovirus Expression system according to the manufacturer's instruction (Invitrogen). Site-specific recombination between entry vectors (BAMBI-pENTR) and the adenoviral destination vector (pAd/PL-DEST) were established with LR Clonase II (Invitrogen). The control adenovirus (Ad-LacZ) was obtained from R.H. Unger (University of Texas Southwestern Medical Center, Dallas, TX, USA). Virus (100 MOI) was added to the cells and then incubated for $6 \mathrm{~h}$ at $37^{\circ} \mathrm{C}$. After conventional culturing of the cells for $48 \mathrm{~h}$, the cells were collected to perform the experiment.

Histological and immunohistochemical studies. Tissue sections $(5 \mu \mathrm{m})$ were stained with hematoxylin and eosin (H\&E) dye for light microscopy. Immunohistochemical staining was performed under the Dako Envision system (Dako, Carpinteria, CA, USA) and was immunostained with antibody against BAMBI (R\&D Systems, Minneapolis, MN, USA).

MTT assay for cell proliferation. The viability of cultured cells was determined by assaying the reduction of 3-(4,5-dimethylthiazol-2-yl)-2,5-diphenyltetrazolium bromide (MTT) to formazan. After transfection with BAMBI adenovirus (100 MOI) or siRNA, the cells in 96-well plates were washed twice with PBS and MTT (100 $\mu \mathrm{g} / 100 \mu \mathrm{l}$ of PBS) was added to each well. Cells were then incubated at $37^{\circ} \mathrm{C}$ for $1 \mathrm{~h}$, and DMSO $(100 \mu \mathrm{l})$ was added to dissolve the formazan crystals. Absorbance was measured at $570 \mathrm{~nm}$ with a model SpectraMax Plus (Molecular Devices, Sunnyvale, CA, USA).

Wound healing assay. Cells were seeded at a density of $10^{6}$ in 6-well plates and then cultured for $24 \mathrm{~h}$. A wound was made using the tip of a pipette as previously described (14). After $8 \mathrm{~h}$, the cells were fixed with $3 \%$ formaldehyde in PBS for $15 \mathrm{~min}$ and images of the wound were generated using different fields.

Matrigel invasion assay. The invasion assays were carried out using a chemotaxis chamber (BD Biosciences, San Jose, CA, USA) and coated with $10 \mu \mathrm{g} / \mathrm{ml}$ Matrigel (BD Biosciences). Then, $100 \mu \mathrm{l}$ of $10^{5}$ cells $/ \mathrm{ml}$ suspension was introduced into each well. Thus, the cells were allowed to invade for $24 \mathrm{~h}$ and then fixed with methanol. This was followed by crystal violet staining.

Gelatin zymography. The activities of two enzymes, matrix metalloproteinase (MMP)-2 and -9 were assayed by gelatin zymography (16). Samples of serum-free conditioned medium 
Table I. Sequences and accession numbers for forward and reverse primers for the real-time RT-PCR.

\begin{tabular}{|c|c|c|}
\hline Gene & Sequences for primers & Accession no. \\
\hline$\beta$-catenin & $\begin{array}{l}\text { Forward: ATTGTCCACGCTGGATTTTC } \\
\text { Reverse: TCGAGGACGGTCGGACT }\end{array}$ & NM_001904 \\
\hline c-Myc & $\begin{array}{l}\text { Forward: CACCGAGTCGTAGTCGAGGT } \\
\text { Reverse: TTTCGGGTAGTGGAAAACCA }\end{array}$ & NM_002467 \\
\hline $\mathrm{p} 21$ & $\begin{array}{l}\text { Forward: CATGGGTTCTGACGGACAT } \\
\text { Reverse: AGTCAGTTCCTTGTGGAGCC }\end{array}$ & NM_000389 \\
\hline CDK2 & $\begin{array}{l}\text { Forward: GAATCTCCAGGGAATAGGGC } \\
\text { Reverse: TGGTACCGAGCTCCTGAAAT }\end{array}$ & NM_001798 \\
\hline CDK6 & $\begin{array}{l}\text { Forward: TGTCTGTTCGTGACACTGTGC } \\
\text { Reverse: ATGCCGCTCTCCACCAT }\end{array}$ & NM_001259 \\
\hline MMP-2 & $\begin{array}{l}\text { Forward: GGAAAGCCAGGATCCATTTT } \\
\text { Reverse: ATGCCGCCTTTAACTGGAG }\end{array}$ & NM_004530 \\
\hline MMP-9 & $\begin{array}{l}\text { Forward: TTGGTCCACCTGGTTCAACT } \\
\text { Reverse: ACGACGTCTTCCAGTACCGA }\end{array}$ & NM_004994 \\
\hline BAMBI & $\begin{array}{l}\text { Forward: GGCAGCATCACAGTAGCATC } \\
\text { Reverse: GATCGCCACTCCAGCTACAT }\end{array}$ & NM_012342 \\
\hline Cyclin D1 & $\begin{array}{l}\text { Forward: GGCGGATTGGAAATGAACTT } \\
\text { Reverse: TCCTCTCCAAAARGCCAGAG }\end{array}$ & NM_053056 \\
\hline
\end{tabular}

were electrophoresed on a $10 \%$ SDS-polyacryamide gel. After electrophoresis, the gel was washed in $2.5 \%$ Triton $\mathrm{X}-100$ for $1 \mathrm{~h}$ and then incubated at $37^{\circ} \mathrm{C}$ for $24 \mathrm{~h}$ in activation buffer (50 $\mathrm{mM}$ Tris- $\mathrm{HCl}, \mathrm{pH} 7.5,150 \mathrm{mM} \mathrm{NaCl}, 10 \mathrm{mM} \mathrm{CaCl}_{2}$ and $0.02 \% \mathrm{NaN}_{3}$ ). After staining with Coomassie brilliant blue R-250, enzymatic activities were detected as clear bands against the blue background.

Cell cycle analysis. Cells $\left(1-5 \times 10^{5}\right)$ in 6 -well plates were transfected with Ad-BAMBI, Ad-LacZ (100 MOI) or BAMBI siRNA and control siRNA for $48 \mathrm{~h}$. After trypsinization and collection, cells were washed three times with PBS and fixed in $70 \%$ ethanol overnight at $4^{\circ} \mathrm{C}$. Cells were then washed three times in PBS with $0.1 \%$ BSA. Cells were incubated with $5 \mathrm{mg} / \mathrm{ml}$ of RNase A (DNase free) and $50 \mathrm{mg} / \mathrm{ml}$ of PI for $90 \mathrm{~min}$ at $4^{\circ} \mathrm{C}$. The percentages of cells in different phases of the cell cycle were measured with a FACStar flow cytometer (Becton-Dickinson, San Jose, CA, USA).

Western blot analysis. The homogenized osteosarcoma tissues or cells were kept in lysis buffer (M-PER; Thermo Scientific). The lysates were separated by $10 \%$ SDS-PAGE and transferred to PVDF membranes (Millipore, Billerica, MA, USA) by electroblotting. After blocking with 5\% skim-milk, the blot was probed with primary antibodies for BAMBI (R\&D Systems), $\beta$-catenin, cyclin D1, CDK2, CDK6, p21 and $\beta$-actin (all from Santa Cruz Biochemicals, Santa Cruz, CA, USA).

$R N A$ isolation and the real-time RT-PCR analysis. Total RNA was extracted from the cells using the TRIzol reagent (Invitrogen). First-strand cDNA was generated using the random hexamer primer provided in the first-strand cDNA synthesis kit (Applied Biosystems, Foster City, CA, USA). Specific primers for each gene (Table I) were designed using Primer Express software (Applied Biosystems). The PCR reaction was carried out by the ABI Prism 7900HT Sequence Detection system (Applied Biosystems). All the experiments were performed in triplicate.

Statistical analysis. Statistical analysis of the data was performed using ANOVA and Duncan's test. Differences with a P-value $<0.05$ were considered to indicate a statistically significant result.

\section{Results}

The overexpression of BAMBI in human osteosarcoma tissues. To assess the effects of BAMBI on the pathogenesis of osteosarcoma, we analyzed the degree of BAMBI expression using immunohistochemical studies and western blot analysis in human osteosarcoma and normal tissues. The western blot analysis showed that the degree of BAMBI expression was 4-fold higher in osteosarcoma tissues as compared with normal tissues (Fig. 1A and B). In addition, the degree of $\beta$-catenin expression was also significantly higher in osteosarcoma tissues (Fig. 1A and B). Immunohistochemical studies showed that the BAMBI expression was observed in the cytoplasm of human osteosarcoma cells (Fig. 1C).

Effects of BAMBI on the migration and invasion of human osteosarcoma cells. After transfection with BAMBI adenovirus or BAMBI siRNA for $48 \mathrm{~h}$, we analyzed the migration 
A

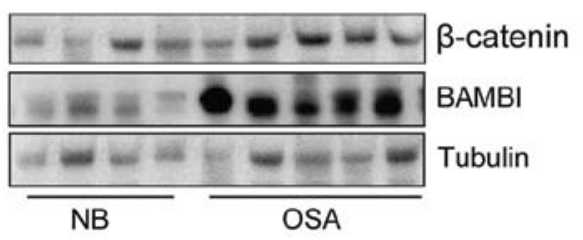

B

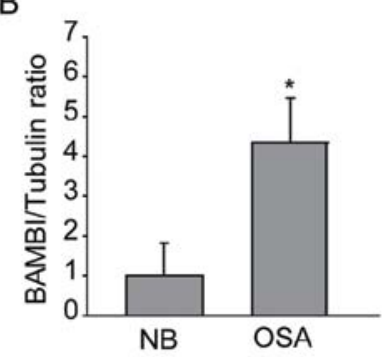

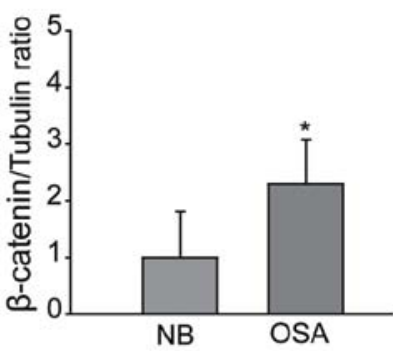

C
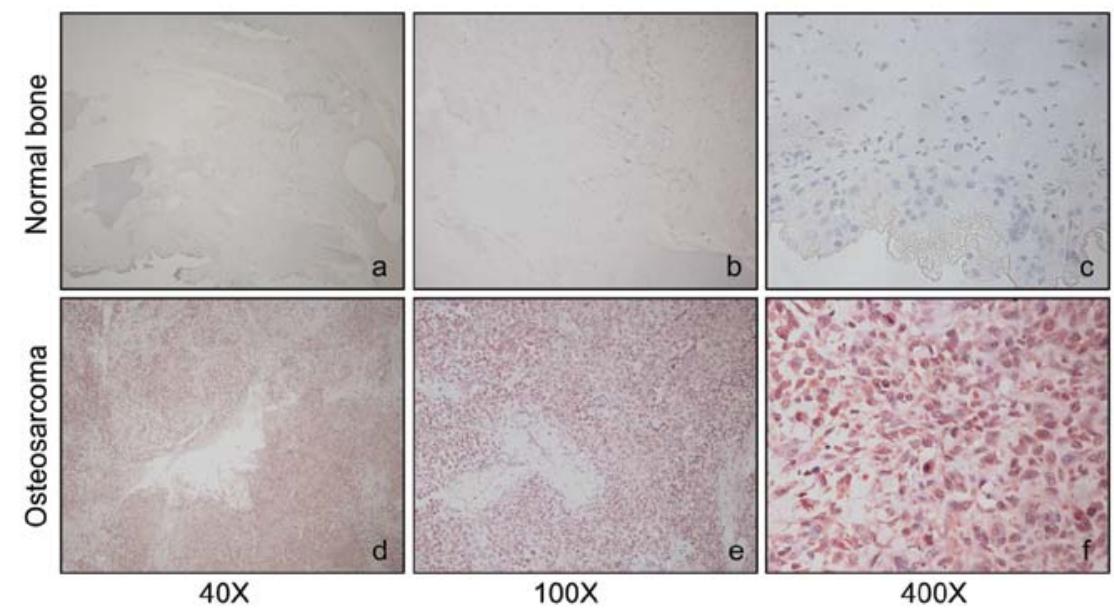

Figure 1. Expression of BAMBI in human osteosarcoma tissues. Expression of BAMBI and $\beta$-catenin proteins in normal or osteosarcoma tissues (A) and a densitometric analysis of both proteins (B). Expression of BAMBI in normal (a, b and c) or osteosarcoma (d, e and f) tissues by immunohistochemical staining (C). "Significantly different from the normal; ${ }^{*} \mathrm{P}<0.05$.

(Fig. 2A) and invasion (Fig. 2B) of human osteosarcoma cell line (U2-OS). Moreover, following the transfection, there was a significant change in the migration of U2-OS in the wound healing experiment. In the cells with an overexpression of BAMBI, there was an increase in the invasion of osteosarcoma cells. With the suppression of the expression of BAMBI (knockdown of endogenous BAMBI), the migration and invasion of osteosarcoma cells was effectively blocked. The expression of BAMBI in these cells was confirmed on a western blot analysis (Fig. 2C). The degree of BAMBI expression was subject to the transfection. Moreover, the degree of MMP-2 expression was also associated with that of BAMBI expression. It is generally known that MMP-2 and MMP-9 are released into the culture medium. We, therefore, analyzed the effects of BAMBI based on their activities by zymography (Fig. 2D). This showed that the BAMBI had an effect in improving the activities of MMP-2 and MMP-9.

The effects of BAMBI in inducing the cell proliferation and the transition of $G_{0} / G_{1}$ to $G_{2} / M$ in human osteosarcoma cells. After transfection with BAMBI adenovirus or siRNA for $48 \mathrm{~h}$, cellular proliferation was analyzed in human osteosarcoma cell line U2-OS. According to the MTT analysis, the overexpression of BAMBI was associated with the increased proliferation of osteosarcoma cells by $\sim 189 \pm 5.5 \%$ at $48 \mathrm{~h}$ and $242 \pm 7.5 \%$ at $72 \mathrm{~h}$ (Fig. 3A). We analyzed the effects of BAMBI on the cell cycle regulatory molecules that play a key role in the cell cycle transition. The levels of cyclin D1 and $\beta$-catenin and their associated cyclin-dependent kinases (CDKs), CDK2 and CDK6, were increased in the cells with an overexpression of BAMBI
(Fig. 3B). In these cells, however, the degree of the expression of cell cycle inhibitor, p21, was decreased. Following an analysis of the variability in the degree of BAMBI expression, the cell cycle was determined by fluorescence activated cell sorting (FACS) analysis (Fig. 3C). With the overexpression of BAMBI, the proportion of cells with $\mathrm{G}_{0} / \mathrm{G}_{1}$ DNA copies was decreased to $35.26 \pm 3.41 \%$. In the control group, however, it was $58.36 \pm 3.27 \%$. The proportion of cells with $\mathrm{S}$ and $\mathrm{G}_{2} / \mathrm{M}$ DNA copies was $17.52 \pm 2.52$ and $46.44 \pm 3.83 \%$, respectively, with the overexpression of BAMBI, whereas it was $13.17 \pm 2.31$ and $25.33 \pm 1.96 \%$ in the corresponding order in the control group. In the control group, comprising virus-transfected cells, it did not change; the proportion of cells with $\mathrm{G}_{0} / \mathrm{G}_{1}, \mathrm{~S}$ and $\mathrm{G}_{2} / \mathrm{M}$ DNA copies was $41.81 \pm 3.75,14.22 \pm 3.09$ and $38.35 \pm 3.18 \%$, respectively. Consistent with the findings that the cell growth was increased, the BAMBI promoted the transition from $\mathrm{G}_{0} / \mathrm{G}_{1}$ to $\mathrm{G}_{2} / \mathrm{M}$ in the oteosarcoma cells.

Real-time RT-PCR analysis of oncogenes. The RNA was isolated from cells transfected with BAMBI adenovirus or siRNA. Then, the degree of the expression of several genes related to oncogenesis were analyzed (Fig. 4). The upregulation of BAMBI by adenovirus or downregulation of BAMBI by RNA interference were confirmed by measuring protein levels. The $\beta$-catenin levels were consistent with the modification of BAMBI. There were alterations in the expression of cyclin D1, CDK2, CDK6 and c-Myc, known as Tcf/Lef target genes (17), and the relevant cell cycle genes with the treatment with BAMBI. The degree of the expression of MMP-2 and MMP-9, both of which are involved in the invasion and metas- 


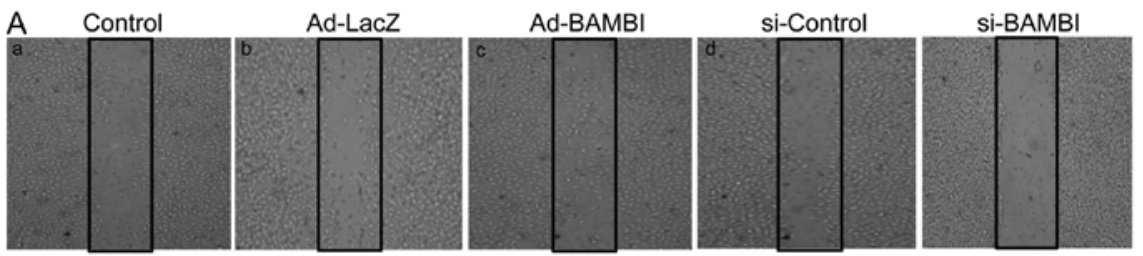

B

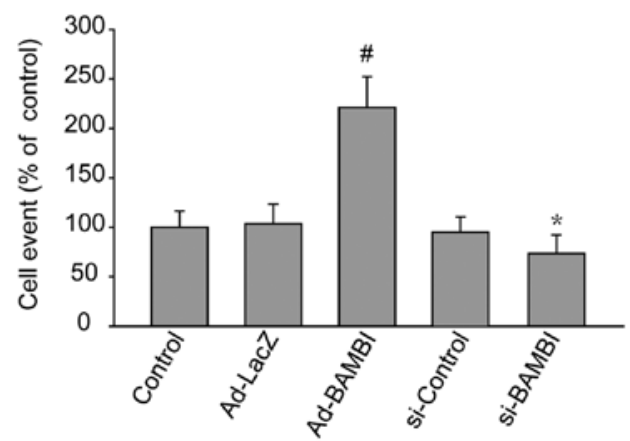

C

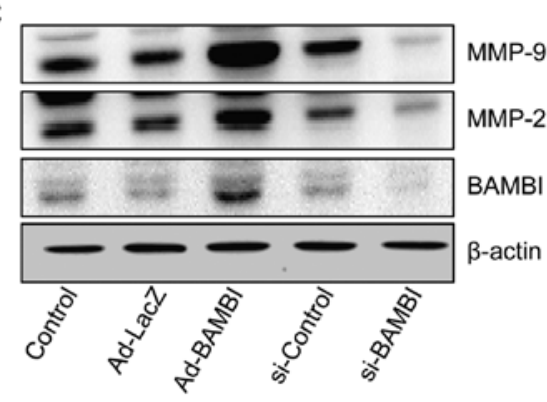

D

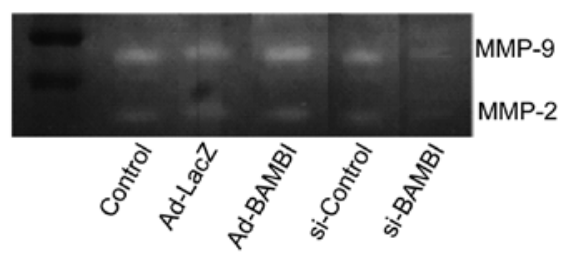

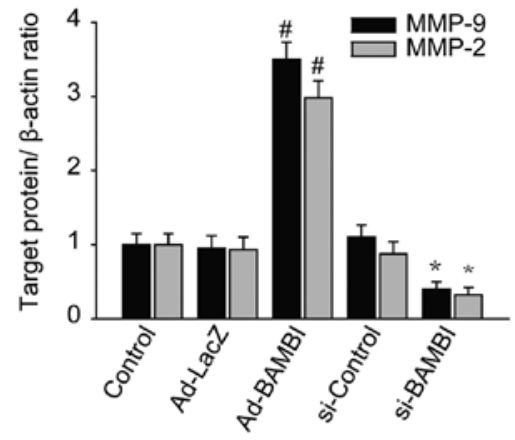

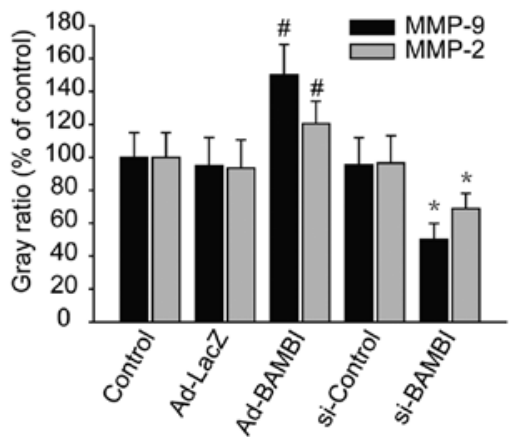

Figure 2. Effects of BAMBI on the migration and invasion of U2-OS and MG63 cells. Cells were infected by Ad-BAMBI, Ad-Lacz or BAMBI siRNA, control siRNA for $48 \mathrm{~h}$. The migration and invasion capacity of the cells were examined by (A) the scratch and (B) the Transwell experiment, representative photographs and histogram figures are shown. MMPs and BAMBI protein level was examined by the degree of MMP expression and was analyzed by (C) western blot analysis and (D) gelatin zymography. The data points in the graph are the means \pm SEM of three independent experiments in U2-OS cells (A). ${ }^{\#} \mathrm{P}<0.05$ vs. Ad-LacZ group, ${ }^{\mathrm{P}}<0.05$ vs. control siRNA group.

tasis of the tumor, was also increased with the overexpression of BAMBI.

\section{Discussion}

To date, it has been demonstrated that the BAMBI signaling plays a role in the pathogenesis of many human malignancies (18). Still, however, little is known about the biological significance of its role in the pathogenesis of osteosarcoma. Previous studies have shown that human osteosarcomas are positive for the expression of both BAMBI and $\beta$-catenin, thus, suggesting that their pathogenesis may be involved in multiple Wnt signaling pathways. The presence of metformin-mediated BAMBI suggests that the pathogenesis of osteosarcoma is associated with the canonical Wnt- $\beta$-catenin pathway (19). Our results provided additional evidence demonstrating that the BAMBI is involved in the pathogenesis of osteosarcoma by altering the degree of $\beta$-catenin expression via the Wnt signaling pathway.

In the present study, we performed immunohistochemistry to compare the degree of BAMBI expression between the normal tissue and the osteosarcoma specimen sampled 
A

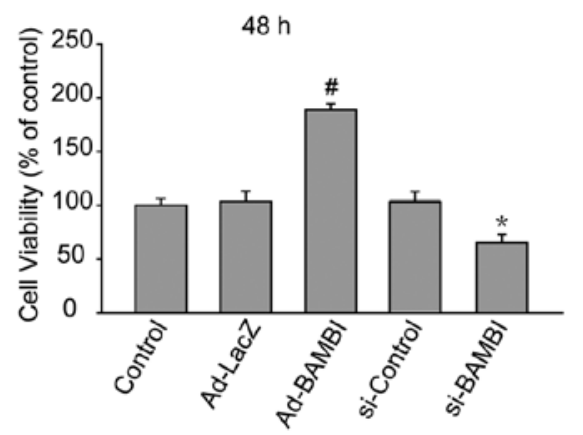

B

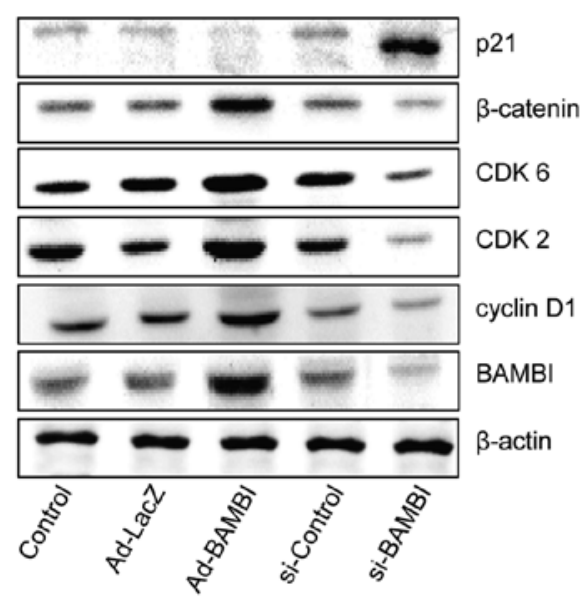

C

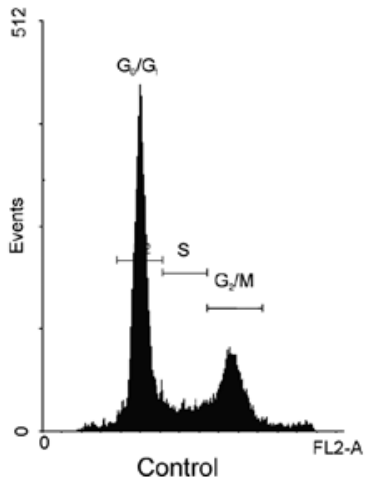

Control
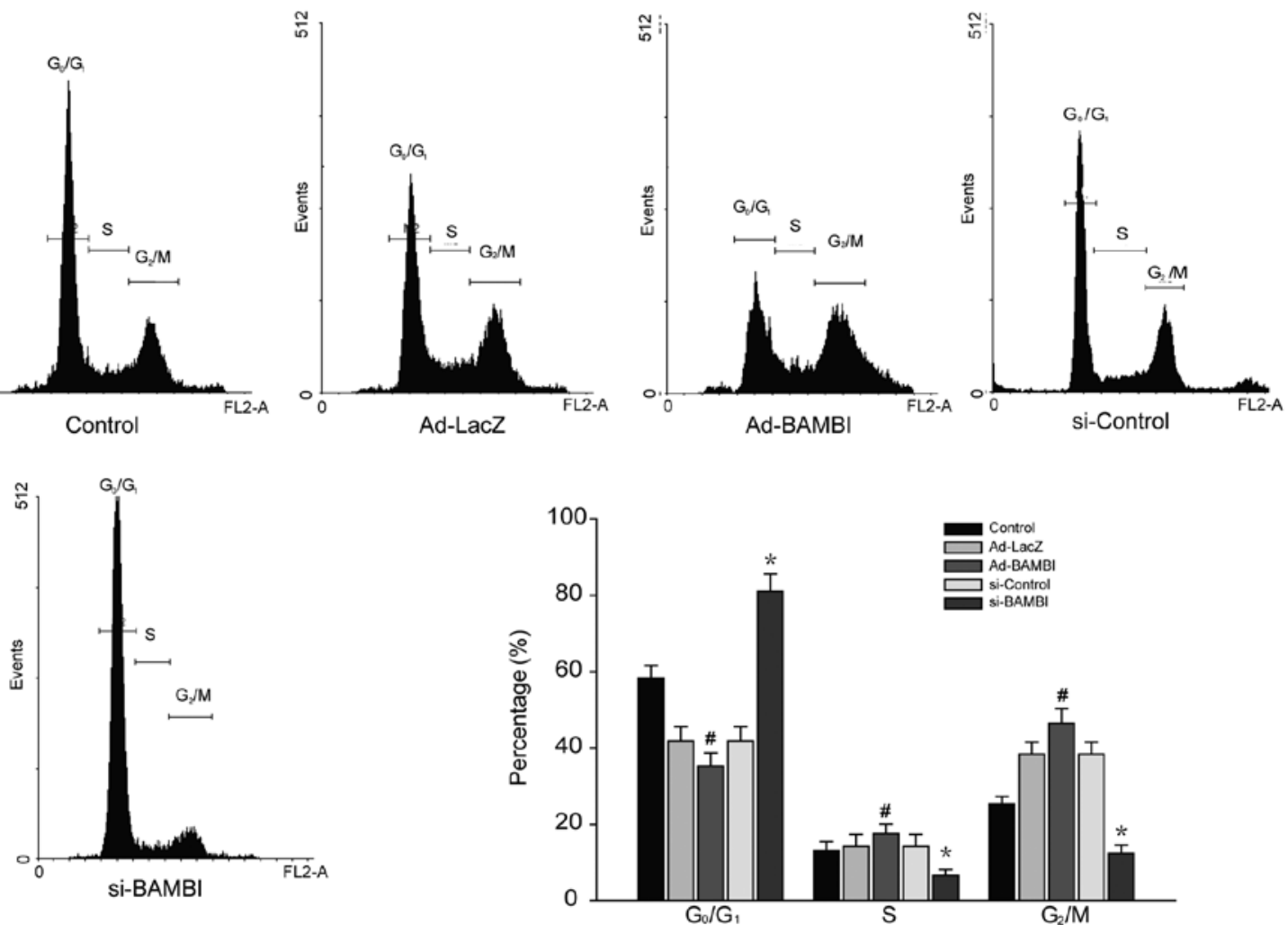

Figure 3. The effects of BAMBI on cell proliferation and cell cycle in human osteosarcoma U2-OS cells. Cells were infected by Ad-BAMBI, Ad-Lacz or BAMBI siRNA, control siRNA for $48 \mathrm{~h}$. (A) Cell viability was determined by the MTT assay and is presented as a calculated percentage of viable cells. (B) The related protein, $\beta$-catenin, cyclin D1, CDK2, CDK6 and p21 were examined by western blotting and a densitometric analysis of each target protein. (C) Cells were collected and then processed for an analysis of cell cycle regulation. Representative histograms of cell cycle distribution in all groups are shown. Each point represents the means \pm SEM of three determinations. ${ }^{\#} \mathrm{P}<0.05$ vs. Ad-LacZ group, ${ }^{*} \mathrm{P}<0.05$ vs. control siRNA group.

from humans. On immunohistochemical staining of the 11 human tissue samples, the degree of BAMBI expres- sion was significantly lower in the normal tissue and that of BAMBI expression was significantly higher in osteosarcoma 

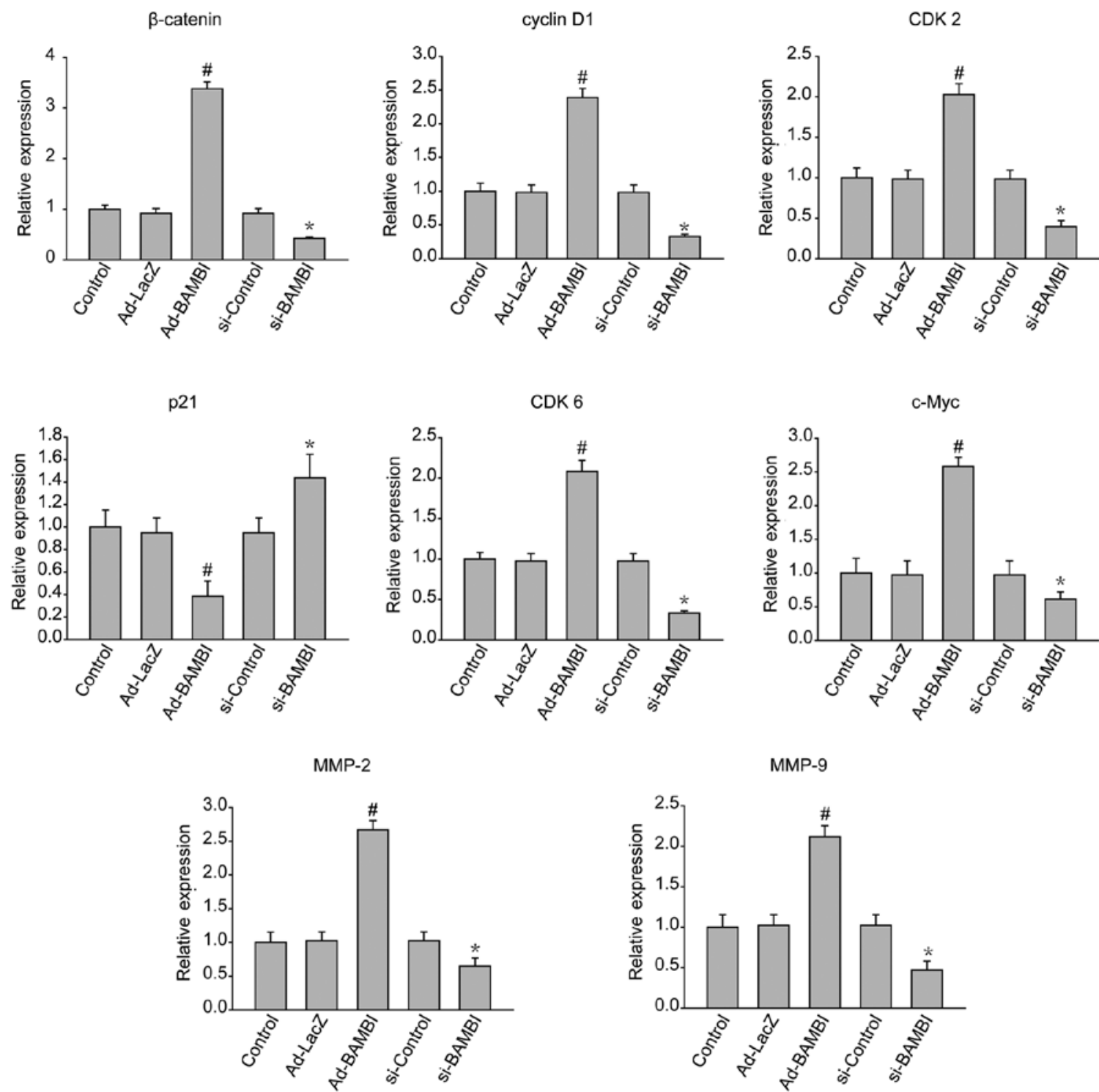

Figure 4. Real-time RT-PCR analysis of oncogenes. Cells were collected and mRNAs were extracted by reagents. Real-time RT-PCR analysis of oncogenes was performed as described in Materials and methods. Each value is the means \pm SEM of at least three samples. ${ }^{\#} \mathrm{P}<0.05$ vs. Ad-LacZ group, ${ }^{*} \mathrm{P}<0.05$ vs. control siRNA group.

specimens. In agreement with these findings, the western blot analysis showed that the degree of BAMBI expression was four times higher in osteosarcoma specimen as compared with the normal tissue. But the degree of $\beta$-catenin expression was significantly higher in the oteosarcoma specimen and it was only 2.5 times higher as compared with the normal tissue.

It has been proposed that the BAMBI plays a role as an antagonist in blocking the signal transduction pathway where the TGF- $\beta$ family proteins are involved. Recent studies have shown that the BAMBI has an effect in regulating the Wnt activity by increasing the response to the transcription of Wnt, as confirmed by the Wnt-responsive LEF-luciferase and TOF-luciferase (20). Furthermore, the BAMBI interacts with receptor Frizzled and LRP-5/6, thus, increasing its effects on the Wnt signaling pathway. In this context, our results demonstrated its effects in stimulating the $\mathrm{Wnt} / \beta$-catenin signaling pathway on the real-time RT PCR analysis. In addition, our results also showed that
BAMBI stimulated nuclear accumulation of $\beta$-catenin. The overexpression of BAMBI in human osteosarcoma cells strongly induces $\beta$-catenin and the Wnt-induced transcription of target genes, cyclin D1 and CDKs. Moreover, the Wnt signaling pathway is blocked by knockdown of endogenous BAMBI.

The Wnt signaling pathway is activated in most human cancers. $\beta$-catenin phosphorylation occurs sequentially by CKI $\alpha$ and GSK3 $\beta$, which is followed by degradation via the ubiquitin-proteasome pathway (21). Loss-of-function mutations of adenomatous polyposis coli and stabilization mutations of $\beta$-catenin lead to the accumulation of $\beta$-catenin (22). A wide spectrum of $\beta$-catenin targets, such as the proteins involved in cell cycle, cell-matrix interactions, migration and invasion, have been identified (23).

The next step of metastasis is the invasion of tumor cells into the basement membrane, where distinct events are involved and these include the cell motility and MMP expression. Invasive 
tumors exhibit active migration and high levels of MMPs (24). Our results showed that the BAMBI might be involved in the upregulation of $\beta$-catenin nuclear translocation in human osteosarcoma cells, thus, suggesting that it has an effect in modulating the activities of the Wnt signaling pathway. It is apparent that the effects of BAMBI in promoting the Wnt signaling pathway are associated with a higher potential of tumor invasion and a higher degree of MMP-2 expression as compared with the cells where the BAMBI expression was blocked. Given that $\beta$-catenin preferentially translocates into the nucleus during the cell migration, it is probable that the BAMBI can increase the motility of osteosarcoma cells by upregulating the nuclear translocation of $\beta$-catenin. Taken together, our results suggest that the degree of metastatic potential would be increased in the cells with an overexpression of BAMBI.

With the nuclear translocation of $\beta$-catenin, target genes, such as cyclin D1 and CDKs, are activated. This leads to the promotion of the growth of tumor cells (25). Cyclin D1, along with $C D K 2$, are the driving forces behind the $\mathrm{G}_{1}-\mathrm{S}$ transition of the cell cycle, whereas p21 induces $G_{1}$ and $G_{2} / M$ phase cell cycle arrest (26). This has been reported in our previous studies (27). Significant increases in $\beta$-catenin, cyclin D1 and CDK6 were observed in the BAMBI-transfected osteosarcoma cells. The increase in these checkpoint proteins leads to uncontrolled cell growth and aberrant cell function and the cells quickly traverse the $\mathrm{G}_{0}$ to $\mathrm{G}_{1}$ and/or $\mathrm{G}_{1}$ to $\mathrm{S}$ transitions. Finally, we found that BAMBI also cooperates with the Wnt not only to stimulate the expression of cyclin D1 and c-Myc but also to promote cell cycle progression.

Osteosarcoma is the most prevalent cancer mainly affecting adolescents and young adults. Due to a delayed diagnosis and a lack of the effective treatments, patients with osteosarcoma are at increased risks of recurrence and distant metastasis (23). Currently, the surgical treatment is the best treatment option. In a clinical setting, however, it is not easy to detect the osteosarcoma at the earliest opportunity possible for surgical treatment. It has become a very important issue to develop the optimal diagnostic and treatment methods for osteosarcoma, which is essential for reducing its incidence and burden.

To summarize, our results showed that BAMBI modulated the Wnt- $\beta$-catenin pathway in vitro in osteosarcoma specimen, thus, suggesting that it can upregulate the invasion and migration of osteosarcoma. In addition, our results showed that BAMBI enhanced the cell viability by regulating the cell cycle in the presence of cyclin D1. Collectively, our results indicate that the BAMBI might have a potential to prevent or treat osteosarcoma.

\section{Acknowledgements}

This study was supported by the National Research Foundation of Korea (NRF) grant funded by the Korea government (MEST) (No. 2011-0028928).

\section{References}

1. Bacci G, Longhi A, Versari M, Mercuri M, Briccoli A and Picci P: Prognostic factors for osteosarcoma of the extremity treated with neoadjuvant chemotherapy: 15-year experience in 789 patients treated at a single institution. Cancer 106: 1154-1161, 2006
2. Ferguson WS and Goorin AM: Current treatment of osteosarcoma. Cancer Invest 19: 292-315, 2001.

3. Bacci G, Briccoli A, Ferrari S, et al: Neoadjuvant chemotherapy for osteosarcoma of the extremities with synchronous lung metastases: treatment with cisplatin, adriamycin and high dose of methotrexate and ifosfamide. Oncol Rep 7: 339-346, 2000.

4. Saeter G, Hoie J, Stenwig AE, Johansson AK, Hannisdal E and Solheim OP: Systemic relapse of patients with osteogenic sarcoma. Prognostic factors for long term survival. Cancer 75 : 1084-1093, 1995.

5. Massague J: TGFbeta in cancer. Cell 134: 215-230, 2008

6. Osuna D and de Alava E: Molecular pathology of sarcomas. Rev Recent Clin Trials 4: 12-26, 2009.

7. Massague J, Blain SW and Lo RS: TGF $\beta$ signaling in growth control, cancer, and heritable disorders. Cell 103: 295-309, 2000.

8. Onichtchouk D, Chen YG, Dosch R, et al: Silencing of TGF- $\beta$ signalling by the pseudoreceptor BAMBI. Nature 401: 480-485, 1999.

9. Fritzmann J, Morkel M, Besser D, et al: A colorectal cancer expression profile that includes transforming growth factor $\beta$ inhibitor BAMBI predicts metastatic potential. Gastroenterology 137: 165-175, 2009.

10. Yan $\mathrm{X}$, Lin $\mathrm{Z}$, Chen $\mathrm{F}$, et al: Human BAMBI cooperates with Smad7 to inhibit transforming growth factor- $\beta$ signaling. J Biol Chem 284: 30097-30104, 2009.

11. Seki E, De Minicis S, Osterreicher CH, et al: TLR4 enhances TGF- $\beta$ signaling and hepatic fibrosis. Nat Med 13: 1324-1332, 2007.

12. van Amerongen R, Mikels A and Nusse R: Alternative Wnt signaling is initiated by distinct receptors. Sci Signal 1: re9, 2008.

13. Nusse R and Varmus HE: Wnt genes. Cell 69: 1073-1087, 1992.

14. Polakis P: Wnt signaling in cancer. Cold Spring Harb Perspect Biol 4: 2012.

15. Lee JH, Song MY, Song EK, et al: Overexpression of SIRT1 protects pancreatic $\beta$-cells against cytokine toxicity by suppressing the nuclear factor- $\kappa \mathrm{B}$ signaling pathway. Diabetes 58: 344-351, 2009

16. Aizawa J, Sakayama K, Kamei S, et al: Effect of troglitazone on tumor growth and pulmonary metastasis development of the mouse osteosarcoma cell line LM8. BMC Cancer 10:51, 2010.

17. Tetsu $\mathrm{O}$ and McCormick F: $\beta$-catenin regulates expression of cyclin D1 in colon carcinoma cells. Nature 398: 422-426, 1999.

18. Khin SS, Kitazawa R, Win N, et al: BAMBI gene is epigenetically silenced in subset of high-grade bladder cancer. Int J Cancer 125: 328-338, 2009.

19. Subramaniam N, Sherman MH, Rao R, et al: Metformin-mediated Bambi expression in hepatic stellate cells induces prosurvival Wnt/ $\beta$-catenin signaling. Cancer Prev Res 5: 553-561, 2012.

20. Lin Z, Gao C, Ning Y, He X, Wu W and Chen YG: The pseudoreceptor BMP and activin membrane-bound inhibitor positively modulates Wnt/ $\beta$-catenin signaling. J Biol Chem 283: 33053-33058, 2008.

21. Liu C, Li Y, Semenov M, et al: Control of $\beta$-catenin phosphorylation/degradation by a dual-kinase mechanism. Cell 108: 837-847, 2002.

22. Morin PJ, Sparks AB, Korinek V, et al: Activation of betacatenin-Tcf signaling in colon cancer by mutations in $\beta$-catenin or APC. Science 275: 1787-1790, 1997.

23. Willert $\mathrm{K}$ and Jones KA: Wnt signaling: is the party in the nucleus? Genes Dev 20: 1394-1404, 2006.

24. Stetler-Stevenson WG, Aznavoorian S and Liotta LA: Tumor cell interactions with the extracellular matrix during invasion and metastasis. Annu Rev Cell Biol 9: 541-573, 1993.

25. Shapiro GI: Cyclin-dependent kinase pathways as targets for cancer treatment. J Clin Oncol 24: 1770-1783, 2006.

26. Xiong Y, Hannon GJ, Zhang H, Casso D, Kobayashi R and Beach D: p21 is a universal inhibitor of cyclin kinases. Nature 366: 701-704, 1993.

27. Zhou L, Park BH, Park JH, et al: Overexpression of the prolyl isomerase PIN1 promotes cell growth in osteosarcoma cells. Oncol Rep 29: 193-198, 2013 